\title{
HISTÓRIA DA EDUCAÇÃO NOS TCCS DE PEDAGOGIA DA UFPA (1983 - 2018)
}

\section{HISTORY OF EDUCATION IN UFPA'S PEDAGOGY FINAL PAPERS (1983 -2018)}

\author{
Jamylle Maia ${ }^{1}$ \\ Universidade Federal do Pará - UFPA \\ Alberto Damasceno ${ }^{2}$ \\ Universidade Federal do Pará - UFPA \\ Luane Tomé ${ }^{3}$ \\ Universidade Federal do Pará - UFPA
}

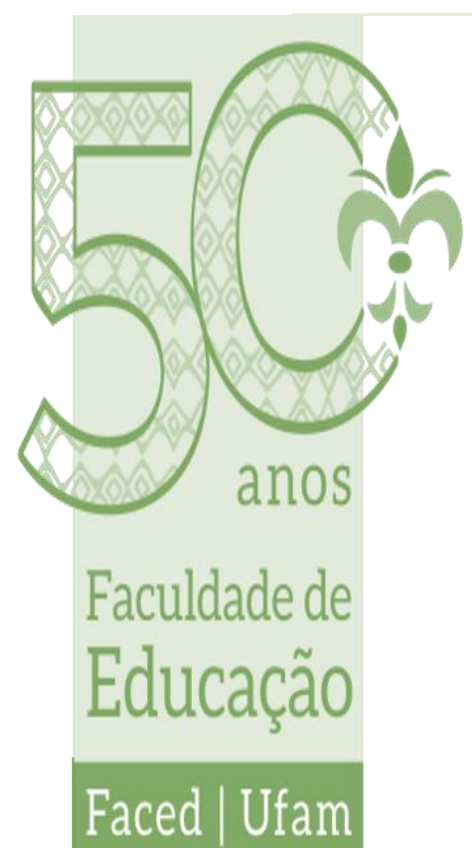

\section{Resumo}

O presente texto tem como propósito elaborar um panorama das produções em História da Educação no Curso de Licenciatura em Pedagogia da Universidade Federal do Pará (UFPA) no campus de Belém, para assim obtermos uma visão do alcance que a temática vem tomando entre os estudantes do citado curso. Para tanto, analisamos os títulos e eixos

\footnotetext{
${ }^{1}$ Graduanda em Pedagogia pela Universidade Federal do Pará (UFPA). Bolsista de Iniciação Científica (PIBIC) do Núcleo de Estudos Transdisciplinares em Educação Básica (NEB) da UFPA. ORCID: https://orcid.org/0000-0003-0194-636X.

E-mail: jamyllepmaia@gmail.com.

2 Professor Titular da Universidade Federal do Pará, docente do Programa de Pósgraduação em Currículo e Gestão da Escola Básica (PPEB) e do Programa de Pósgraduação em Educação na Amazônia (PGEDA). Doutor em Educação pela Pontifícia Universidade Católica de São Paulo (1998). Mestre em Educação Escolar Brasileira pela Universidade Federal de Goiás (1991). Graduado em Arquitetura pela Universidade Federal do Pará (1983). Atualmente coordena o Laboratório de Pesquisas em Memória e História da Educação (LAPEM) e é vice coordenador do Grupo de Estudos em Educação no Pará na Primeira República (GEPRE). Membro da Sociedade Brasileira de História da Educação (SBHE), da Associação Nacional de Pós-Graduação e Pesquisa em Educação (ANPED), da Associação Nacional de Política e Administração da Educação (ANPAE) e do Instituto Histórico e Geográfico do Pará (IHGP), além da coordenação do Fórum Estadual de Educação do Pará. ORCID: http://orcid.org/0000-0003-1620-6735. E-mail: allbertod@ufpa.br.

${ }^{3}$ Graduada em Pedagogia pela Universidade Federal do Pará (UFPA). Mestranda do Programa de Pós-Graduação em Currículo e Gestão da Escola Básica (PPEB) do Núcleo de Estudos Transdisciplinares em Educação Básica (NEB) da UFPA. ORCID: https://orcid.org/0000-0002-1472-7441. E-mail: luanesampaioo@gmail.com.
} 


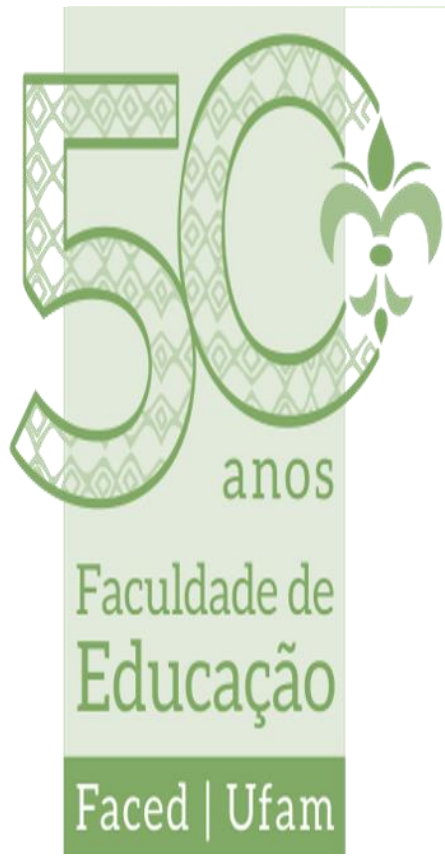

temáticos dessas produções tendo como principais fontes os Trabalhos de Conclusão de Curso (TCC) de entre os anos de 1983 a 2018. Para o desenvolvimento de nosso estudo optamos por adotar a pesquisa que se denomina Estado da Arte. Constatamos, então, que o campo da História da Educação não está entre os temas mais abordados no curso, mas está classificado como de média produção em relação ao todo dos trabalhos catalogados e, além disso, verificamos que os autores dedicaram-se em pesquisar principalmente, sobre as políticas, os desdobramentos históricos e o processo de implantação de Instituições Educativas em variadas épocas.

Palavras-Chave: História da Educação; Produção Acadêmica; Pedagogia.

\section{Abstract}

The purpose of this text is to elaborate an overview of the productions in History of Education in the Pedagogy Degree Course at the Federal University of Pará (UFPA) on the Belém campus, so that we can obtain a view of the scope that the theme has been taking among students of the cited course. For this purpose, the main objective was to analyze the titles and thematic axes of these productions, having as main sources students' Final Papers (Trabalhos de Conclusão de Curso -TCC) between the years 1983 to 2018. For the development of our study, we chose to adopt the research called "state of art". We found, then, that the field of History of Education is not among the topics most covered in the course, but it is classified as of medium production in relation to the whole of the cataloged works and in addition, we verified that the authors dedicated themselves mainly to research on policies, historical developments and the process of implementing Educational Institutions at various times.

Key words: History of Education; Academic Production; Pedagogy.

\section{INTRODUÇÃO}

A temática da História da Educação, ao ser abordada em produções acadêmicas e obras literárias, permite ao leitor uma compreensão mais clara do desenvolvimento histórico de conformação e dos processos educativos tais como são conhecidos nos dias de hoje. É por entendermos sua importância que optamos por analisar as produções desenvolvidas no Curso de Graduação em Pedagogia da Universidade Federal do Pará (UFPA).

Neste sentindo, o presente artigo tem como objetivo apresentar uma visão geral das produções em História da Educação a partir dos Trabalhos de Conclusão de Curso defendidos no mencionado curso, entre os anos de 1983 e 2018. Para atingi-lo propusemo-nos o seguinte questionamento: Quais os temas da História da Educação 


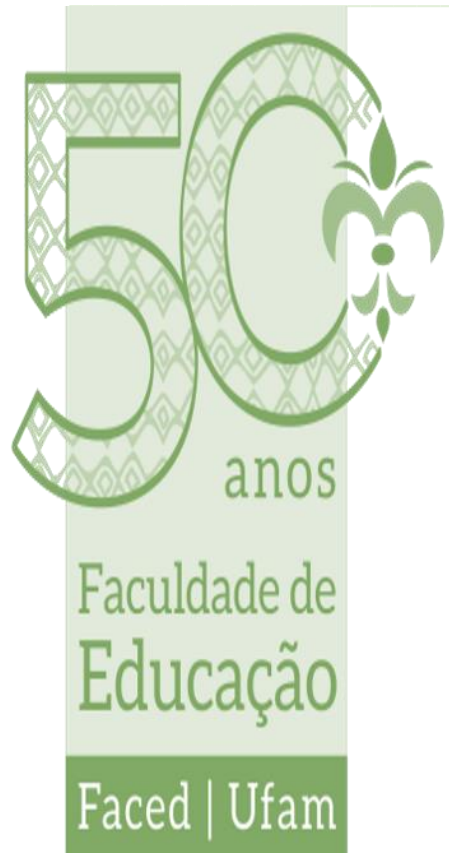

mais abordados nos Trabalhos de Conclusão de Curso dos estudantes do Curso de Pedagogia da UFPA no período de 1983 a $2018 ?$

Para a realização desta tarefa optamos por dividi-la em 3 (três) etapas. A primeira consistiu no levantamento dos TCCs produzidos no período em tela, a partir de informações coletadas junto à biblioteca do Instituto de Ciências da Educação (ICED), unidade acadêmica à qual o curso de Pedagogia está subordinado. A segunda baseou-se na categorização dos TCCs de acordo com as temáticas abordadas ${ }^{4}$. Em terceiro lugar, após sua categorização, identificamos os trabalhos relacionados à pesquisa em História da Educação e passamos a examiná-los de forma mais detalhada, com o intuito de conhecer seu tema e objeto, de acordo com os eixos temáticos definidos pela Sociedade Brasileira de História da Educação $(\mathrm{SBHE})^{5}$, tendo em vista construir uma visão geral acerca do campo da História da Educação ${ }^{6}$ no referido curso.

Para efeito de uma compreensão mais apurada da quantidade e das temáticas de produção, organizamos os trabalhos sob os pontos de vista de sua quantidade e de sua abordagem temática. No primeiro caso, definimos sua produção em faixas de baixa, média ou alta intensidade, de acordo com a frequência com que apareciam em nosso levantamento. Sendo assim, os temas abordados em uma faixa

\footnotetext{
${ }^{4}$ Para tanto, usamos como referências as áreas e subáreas de conhecimento definidas pelo Conselho Nacional de Desenvolvimento Científico e Tecnológico (CNPq), em especial aquelas vinculadas à área da Educação, inserida na grande área "Ciências Humanas".

${ }^{5}$ A Sociedade Brasileira de História da Educação (SBHE) é uma associação que tem como objetivo congregar os profissionais brasileiros que atuam na área da pesquisa e/ou docência em História da Educação. Os trabalhos dos eventos organizados por ela são categorizados a partir de onze eixos temáticos definidos pela SBHE, são eles: Políticas e Instituições Educativas; Intelectuais e Projetos Educacionais; Imprensa e Impressos Educacionais; Formação e Profissão Docente; Educação e Gerações; Disciplinas Escolares e Ensino de História da Educação; Memória e Patrimônio Educativo; Teoria da História e Historiografia da Educação; Educação Profissional; Educação; Movimentos Sociais; Etnias e Gênero e Processos Educativos e Práticas De Sociabilidade Não- Escolares.

${ }^{6}$ A respeito do conceito de campo de história da educação, ver o artigo: HAYASHI \& FERREIRA JUNIOR. O campo da história da educação no Brasil: um estudo baseado nos grupos de pesquisa. Avaliação (UNICAMP), v. 15, p. 167-184, 2010.
} 
de 0 a 50 ocorrências foram definidos como sendo de baixa intensidade. De 51 a 100 trabalhos, a classificamos como sendo de média intensidade. De 101 até 200 trabalhos, ou acima deste número, a classificamos como de alta intensidade. No segundo caso classificamos os trabalhos de História da Educação de acordo com os eixos adotados pela SBHE.

O artigo está estruturado em quatro partes, na primeira fazemos uma introdução geral acerca do estudo; na segunda realizamos uma contextualização acerca da História da Educação e sua importância na formação do professor, em especial no que se refere à formação do licenciado em Pedagogia; na terceira seção fizemos uma breve descrição sobre a história do Curso de Pedagogia da UFPA e dos Trabalhos de Conclusão de Curso de seus estudantes concluintes e, por fim, apresentamos e discutimos os resultados obtidos a partir do levantamento realizado por meio de um olhar ao Estado da Arte que pode ser entendido como "uma metodologia de caráter inventariante e descritivo da produção acadêmica e científica sobre o tema que se busca investigar". (FERREIRA, 2002, p. 258)

Trata-se, também, de um método de natureza bibliográfica que se constitui "em levantamentos do que se conhece sobre determinada área, desenvolvimento de protótipos, de análises de pesquisas ou avaliação da situação da produção do conhecimento da área focalizada" (BRANDÃO, 1986, p.7). Nessa linha de raciocínio, Romanowski e Ens (2006) esclarecem que o estado da arte surgiu com o intuito de mapear e averiguar o conhecimento já produzido entre os pesquisadores e que também é possível compreender através dele a amplitude do que está sendo produzido, assim como perceber se há, entre os temas abordados de uma determinada fonte de produção (como, por exemplo, os TCCs), uma predominância de certas temáticas em detrimento de outras, que, neste caso, são abordadas de forma bem menos significativa. (ROMANOWSKI \& ENS 2006)

Quanto ao método do estado da arte no Brasil, o mesmo entrou em ascensão há cerca de quarenta anos, sendo praticado 


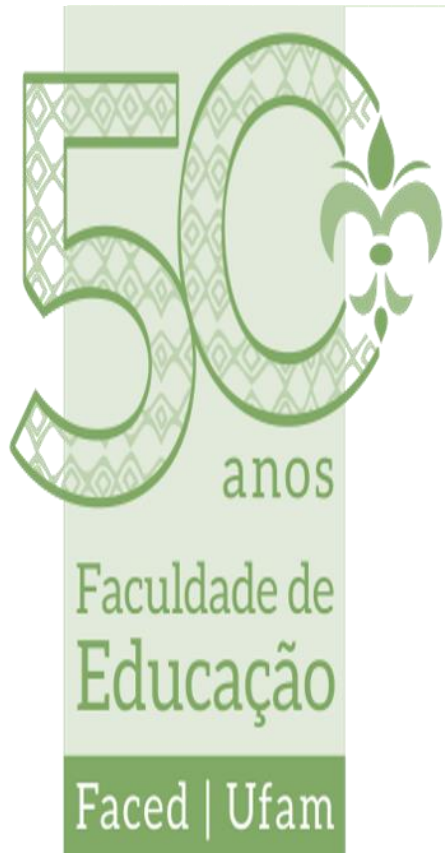

anteriormente em outros países, principalmente nos Estados Unidos e, apesar de ser considerado um método recente entre os brasileiros, tem se mostrado de grande relevância. Pelo fato de este método de estudo ter como um dos objetivos a sistematização do que vem sendo produzido em uma determinada área do conhecimento, o que resulta dele é a possibilidade de perceber a evolução da pesquisa nesta área, identificando, deste modo, os diversos temas abordados pelos trabalhos, inclusive os mais relevantes.

Entretanto, em nosso estudo encontramos uma das dificuldades apontadas por Ferreira (2002) e reforçada por Romanowski e Ens (2006) no que diz respeito aos títulos dos trabalhos pesquisados, pois muitos deles não deixam claro do que trata o estudo, fazendo com que seja necessária a leitura do resumo ou de um trecho maior do corpo do texto. Ainda assim, as dificuldades permaneceram devido à fragilidade na criação de alguns deles, pois alguns resumos não apresentavam os elementos fundamentais pertencentes a um trabalho acadêmico como, por exemplo, o tipo de pesquisa feita e até mesmo o objetivo do trabalho. Além disso, as palavras-chave muitas vezes não faziam referência à essência da pesquisa. Buscamos ainda contribuição teórica nos trabalhos de Alves, Nery e Silva (2019); e de Bencostta (2019), autores que também fazem uma análise de produções científicas, porém em outros contextos e áreas de conhecimento.

\section{A IMPORTÂNCIA DOS ESTUDOS EM HISTÓRIA DA EDUCAÇÃO}

Se, para Saviani (2008), "a construção da memória histórica da educação brasileira pode ser abordada a partir de três vetores: a preservação da memória; o ensino de história da educação; a produção historiográfica propriamente dita" (p. 153), consideramos que este trabalho se enquadra no último vetor apresentado pelo autor.

Nesse sentido, por acreditarmos ser importante a compreensão do leitor a respeito do conceito de historiografia, buscamos em diferentes fontes os estudos acerca desse termo. De forma direta, 


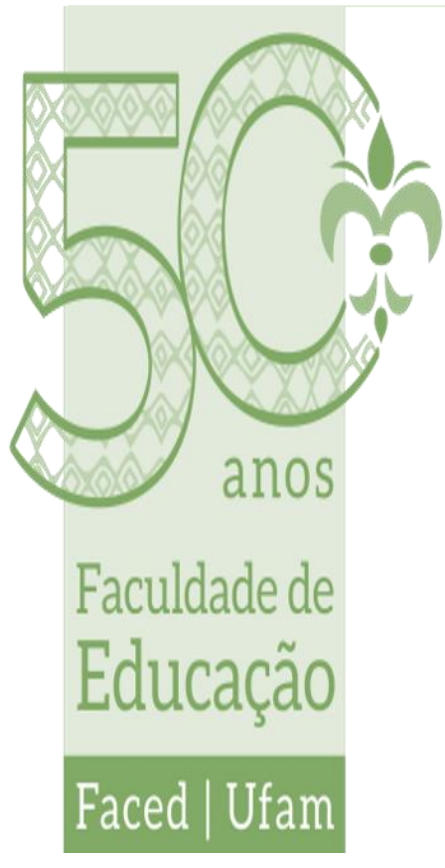

historiografia "é a reflexão sobre a produção e a escrita da História" (SILVA; SILVA, 2005, p. 189). Esses mesmos autores afirmam também que "a maioria dos estudiosos concorda que a historiografia é uma disciplina imprescindível para o historiador. Sem ela, sem conhecer o que já se produziu em sua área de estudos, dificilmente ele poderá elaborar uma reflexão crítica." (SILVA \& SILVA, 2005, p. 192)

Segundo estudos feitos por Cordeiro (2015), o termo historiografia "remete ao produto final do ofício do historiador, podendo ainda ser entendido como conjunto de obras históricas produzidas por historiadores ao longo do tempo" (CORDEIRO, 2015, p.1). Nesta linha de pensamento, realizamos o levantamento da produção historiográfica, uma vez que somente a partir dela é possível refletir sobre as temáticas adotadas.

O presente trabalho baseia-se na ideia de que a História da Educação tem importância fundamental na formação do educador. Nesse sentido, Saviani (2008) é enfático quanto à importância de conhecer a história e estudar o passado e as gerações anteriores. Segundo ele, deve-se considerar que os homens se formam, conhecem a si mesmos e têm consciência do que são por meio da história; daí decorre o fato de que o conhecimento histórico é essencial para o homem, pois:

Tendo em vista que a realidade humana de cada indivíduo se constrói na relação com os outros e se desenvolve no tempo, a memória se configura como uma faculdade específica e essencialmente humana e atinge sua máxima expressão quando se manifesta como memória histórica (SAVIANI, 2008, p. 151).

Isto é, a história de todos os homens nada mais é que a história da relação de cada um com os outros que o cercam em seu dia a dia. O autor segue sua abordagem e menciona a "memória histórica", afirmando que ela está sendo perdida atualmente. Por isso, cita Hobsbawn, quando este afirma que o ofício dos historiadores é lembrar o que os outros esquecem (HOBSBAWN citado por SAVIANI 2008, p. 152), cabendo a eles lembrarem a todos os seres humanos 


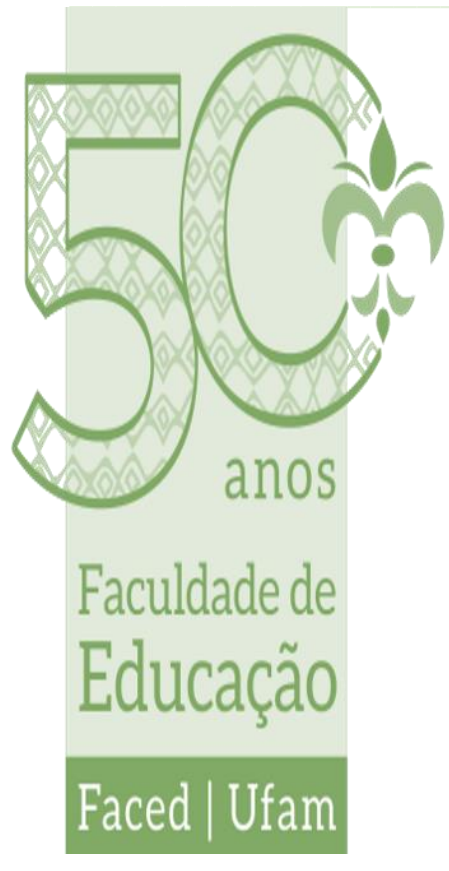

os acontecimentos históricos que levaram a humanidade e o mundo a estarem da forma em que se encontram hoje. Em síntese, "[...] os avanços e recuos, os problemas que os educadores enfrentam são produtos de construções históricas" (SAVIANI, 2008, p. 152). Isso nos leva a compreender que os historiadores são agentes importantes na retomada cada vez mais intensa, dos conhecimentos históricoeducativos.

Feitas essas considerações, a partir das reflexões de Demerval Saviani acerca da fundamentalidade da História da Educação, percebe-se a relevância de investigar as produções feitas em um curso de formação de professores, neste caso, o Curso de Pedagogia da UFPA, o que nos possibilita elencar os temas mais abordados por seus concluintes na etapa final da sua graduação acadêmica.

\section{A PRODUÇÃO DOS TCCS DO CURSO DE PEDAGOGIA DA UFPA}

Segundo o atual Projeto Pedagógico do Curso de Pedagogia da UFPA, aprovado em 2011 pela Resolução no 4.102 de 23 de fevereiro de 2011, o Curso foi fundado há cerca de 66 anos, no ano de 1954, através do Decreto no 35.456/54 e da Portaria do MEC no 771/54 reconhecendo oficialmente o Curso de pedagogia, cujo principal objetivo é formar o pedagogo em nível superior para atuar na área da docência, tanto na Educação Infantil e no Ensino Fundamental, como na gestão e coordenação pedagógica de unidades educacionais escolares e não escolares. No atual projeto, fica patente que o pedagogo tenha uma formação voltada a uma perspectiva crítica, interdisciplinar e contextualizada.

O Trabalho de Conclusão de Curso (TCC), de acordo com o Projeto Pedagógico do Curso, é um componente curricular obrigatório e se caracteriza como um trabalho acadêmico em que são avaliados os conhecimentos obtidos pelo discente no decorrer do curso, devendo o mesmo ser apresentado em sessão pública.

Desta forma, o TCC constitui-se no resultado final de estudo onde o discente deve fazer uma análise sobre um assunto com o qual 


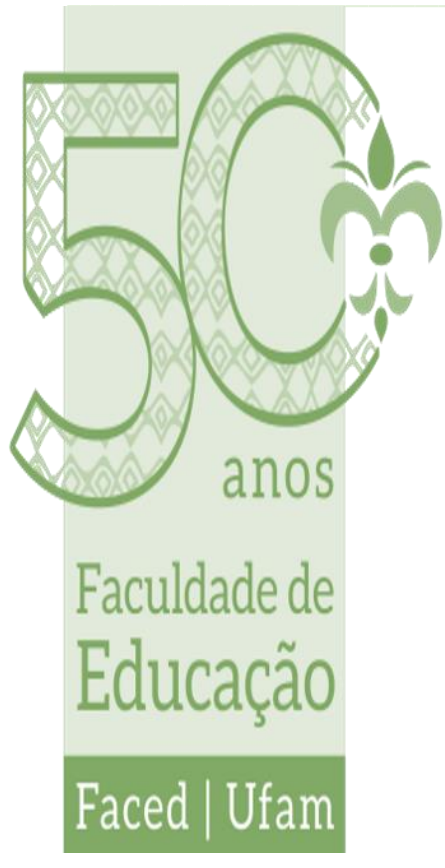

ele se identifica (ASSOCIAÇÃO BRASILEIRA DE NORMAS TÉCNICAS, 2011), além disso, seguirá as orientações de um docente que auxiliará o aluno na elaboração do trabalho, sugerindo leituras e abordagens sobre o tema que será pesquisado. No âmbito da Universidade Federal do Pará, a Resolução № 2.515 de 17 de outubro de 1997 orientava os discentes e docentes quanto aos Trabalhos de Conclusão de Curso, e nela foram fixadas diretrizes gerais para a elaboração do TCC. No Art. $5^{\circ}$ desta Resolução, é estabelecido que - TCC pode ser realizado na forma de monografia de iniciação científica.

Apenas 14 anos depois foi baixada a Resolução N. $\cong 01$ de 15 de junho de 2011 da Faculdade de Educação da UFPA, com base na Resolução no 3.633 de 18 de fevereiro de 2008-CONSEPE/ UFPA, que está vigorando atualmente. Entre outros dispositivos, ela estabelece uma diversificação das modalidades de trabalho, ou seja, a partir desta Resolução, a monografia deixou de ser a única forma possível de Trabalho de Conclusão de Curso, passando a ser acompanhada de outras formas de trabalho como o relato de experiência, o memorial da formação acadêmico-profissional, a pesquisa empírica ou bibliográfica/documental sobre um tema do campo educacional, o plano de intervenção educacional ou o artigo.

Portanto, com o intuito de difundir os principais temas abordados pelas produções analisadas, apresentamos no Quadro 1 as temáticas dos Trabalhos de Conclusão de Curso defendidos entre 1983 e 2018, expostas de acordo com as especialidades definidas pelo CNPQ. No referido quadro estão contidas a quantidade e a porcentagem aproximadas de todos os TCCs defendidos no curso, o que resulta em um total de 1.965 (mil novecentos e sessenta e cinco) trabalhos. 


\begin{tabular}{|c|c|c|c|c|}
\hline & \multicolumn{4}{|c|}{$\begin{array}{l}\text { Tabela } 1 \text { - Quantidade de TCCs defendidos e suas respectivas } \\
\text { temáticas no Curso de Pedagogia da UFPA (1983-2018) }\end{array}$} \\
\hline \multirow{12}{*}{$\begin{array}{l}\text { Faculdade de } \\
\text { Educação }\end{array}$} & SUBÁREA & ESPECIALIDADE & QUANTIDADE & PERCENTUAL \\
\hline & \multirow{6}{*}{$\begin{array}{l}\text { Fundamentos da } \\
\text { Educaçãa }\end{array}$} & Filosofia da Educação & 23 & $1,17 \%$ \\
\hline & & História da Educação & 61 & $3,05 \%$ \\
\hline & & Sociologia da Educação & 40 & $2,04 \%$ \\
\hline & & Antropologia Educacional & 4 & $0,20 \%$ \\
\hline & & Economia da Educação & 5 & $0,25 \%$ \\
\hline & & Psicologia Educacional & 161 & $8,20 \%$ \\
\hline & \multirow{2}{*}{$\begin{array}{l}\text { Administração } \\
\text { Educacional }\end{array}$} & Administração de Sistemas Educacionais & 54 & $2,75 \%$ \\
\hline & & Administração de Unidades Educativas & 15 & $0,76 \%$ \\
\hline & \multirow{3}{*}{$\begin{array}{l}\text { Planejamento e } \\
\text { avaliação } \\
\text { Educacional }\end{array}$} & Política Educacional & 172 & $8,76 \%$ \\
\hline & & Planejamento Educacional & 35 & $1,78 \%$ \\
\hline & & $\begin{array}{l}\begin{array}{l}\text { Avaliação de Sistemas, Instituições, Planos e Programas } \\
\text { Educacionais }\end{array} \\
\end{array}$ & 55 & $2,80 \%$ \\
\hline \multirow{18}{*}{ Faced | Ufam } & \multirow{4}{*}{$\begin{array}{l}\text { Ensino- } \\
\text { aprendizagem }\end{array}$} & Teorias da Instrução & 51 & $2,60 \%$ \\
\hline & & Métodos e Técnicas de Ensino & 157 & $7,99 \%$ \\
\hline & & \begin{tabular}{|l|} 
Tecnologia Educacional \\
\end{tabular} & 38 & $1,93 \%$ \\
\hline & & Avaliação da Aprendizagem & 105 & $5,35 \%$ \\
\hline & \multirow{2}{*}{ Currículo } & Teoria Geral de Planejamento e Desenvolvimento Curricular & 29 & $1,48 \%$ \\
\hline & & Currículos Específicos para Níveis e Tipos de Educação & 101 & $5,14 \%$ \\
\hline & \multirow{2}{*}{$\begin{array}{l}\text { Orientação e } \\
\text { Aconselhamento }\end{array}$} & Orientação Educacional & 38 & $1,93 \%$ \\
\hline & & Orientação Vocacional & 1 & $0,05 \%$ \\
\hline & \multirow{7}{*}{$\begin{array}{l}\text { Tópicos } \\
\text { específicos de } \\
\text { educação }\end{array}$} & Educação de Adultos & 75 & $3,82 \%$ \\
\hline & & Educação Permanente & 75 & $3,82 \%$ \\
\hline & & Educação Rural & 82 & $4,18 \%$ \\
\hline & & Educação em Periferias Urbanas & 16 & $0,81 \%$ \\
\hline & & Educação Especial & 166 & $8,45 \%$ \\
\hline & & Educação Pré-Escolar & 226 & $11,51 \%$ \\
\hline & & Ensino Profissionalizante & 17 & $0,87 \%$ \\
\hline & \multirow{2}{*}{$\begin{array}{l}\text { Subáreas não } \\
\text { especificadas } \\
\text { pelo CNPQ }\end{array}$} & Educação Ambiental & 101 & $5,14 \%$ \\
\hline & & Pedagogia em Organizações Sociais & 62 & $3,16 \%$ \\
\hline & \multicolumn{2}{|l|}{ TOTAL } & 1965 & $100,00 \%$ \\
\hline
\end{tabular}

Fonte: Elaborado pelos autores, baseado em dados da Biblioteca Setorial do ICED/UFPA.

Como podemos constatar, a temática mais frequente entre os TCCs defendidos é a da "Educação Pré-Escolar", com 11,51\% do total de trabalhos, seguida da temática "Política Educacional", com 8,76\%, e a temática "Educação Especial" como a terceira mais frequente, com $8,45 \%$. Além destas, as temáticas que aparecem com alta intensidade são "Psicologia Educacional", com 8,20\%; "Métodos e técnicas de Ensino", com 7,99\%; "Avaliação de Aprendizagem", com 5,35\%; "Currículos Específicos para Níveis e Tipos de Educação" e "Educação Ambiental" aparecem empatadas com a mesma quantidade, cada uma com $5,14 \%$. Todas essas temáticas acima 


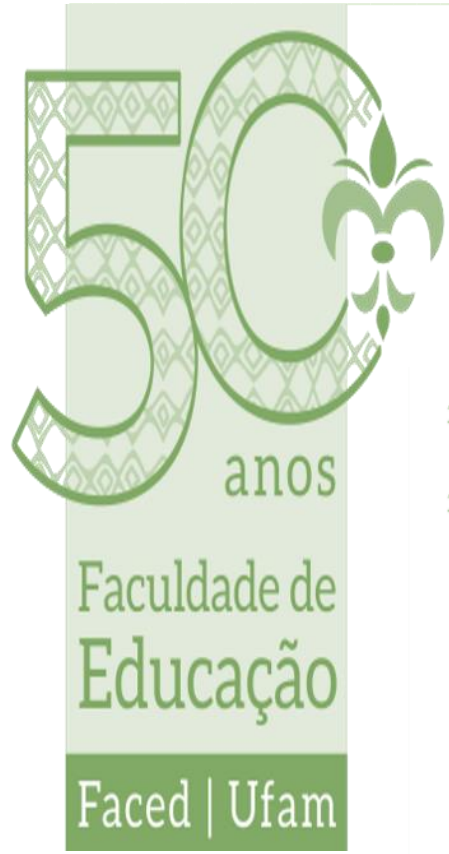

mencionadas foram abordadas em mais de 100 trabalhos, por isso consideramos como sendo uma produção de alta intensidade.

Figura 1 - Quantidade de Trabalhos de Conclusão de Curso

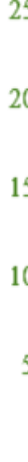

200
50
00
50
0

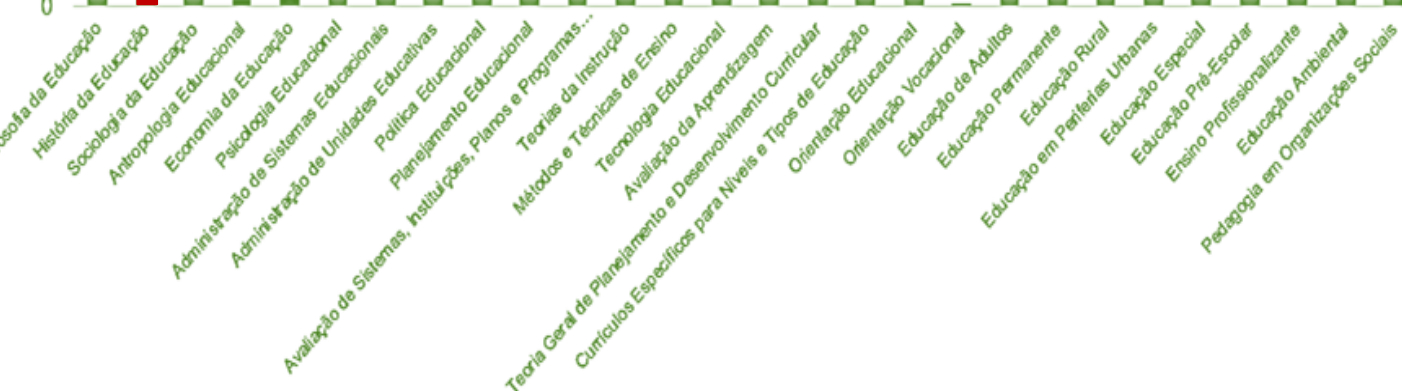

Fonte: Elaborado pelos autores, baseado em dados da Biblioteca Setorial do ICED.

As temáticas apontadas como de produção de média intensidade são "Educação Rural", com 4,18\%; "Educação Permanente" e "Educação de Adultos", ambas com 3,82\%; "Pedagogia em Organizações Sociais", com 3,16\%; "História da Educação", com 3,05\%; "Avaliação de Sistemas, Instituições, Planos e Programas Educacionais", com 2,80\%. "Administrações de Sistemas Educacionais", com 2,75\%; e, por fim, "Teorias da Instrução", com 2,60\%.

Com baixo índice de abordagem temos "Orientação Vocacional", "Antropologia Educacional" e "Economia da Educação", cada uma com 0,05\%, 0,20\% e 0,25\% respectivamente. Além delas, surgem "Administração de Unidades Educativas", com 0,76\%; "Educação em Periferias Urbanas", com 0,81\%; Ensino Profissionalizante, com 0,87\%; "Filosofia da Educação", com 1,17\%; "Planejamento Educacional”, com 1,78\%; "Tecnologia Educacional” e 


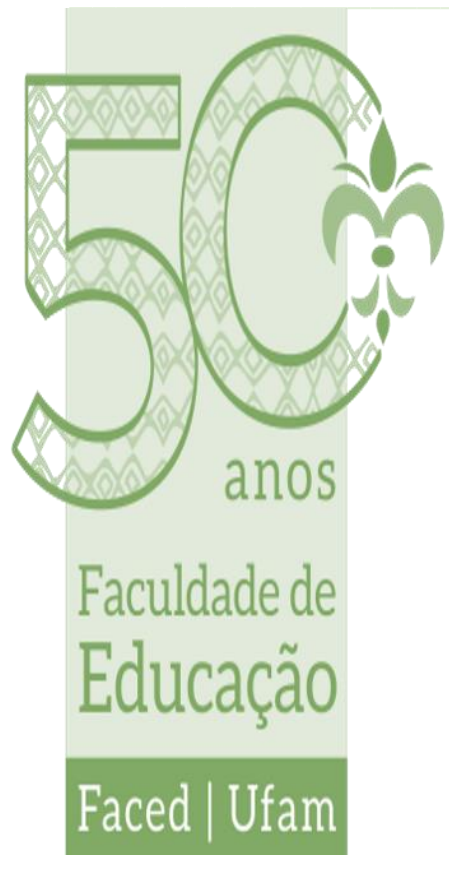

"Orientação Educacional”, as duas com 1,93\%; e, finalmente, "Sociologia da Educação", com 2,04\%. Dessa forma, inferimos que as temáticas citadas anteriormente podem ser classificadas como produção de baixa intensidade. Em relação à História da Educação, objeto principal deste estudo, vimos que se encaixa na faixa de média intensidade, apesar de ser considerada uma temática essencial para a formação do educador, como vimos anteriormente.

Para empreender a análise das temáticas mais abordadas entre os trabalhos do campo da História da Educação, relacionamos seus títulos e os enquadramos nos eixos temáticos adotados pela Sociedade Brasileira de História da Educação, produzindo o quadro a seguir:

Tabela 2 - Títulos e eixos temáticos dos Trabalhos de Conclusão de Curso da área de História da Educação entre 1983 e 2018 no Curso de Pedagogia da UFPA.

\begin{tabular}{|c|c|c|c|}
\hline ANO & TÍTULO DOS TRABALHOS & AUTORES & EIXOS TEMÁTICOS \\
\hline 1983 & $\begin{array}{l}\text { A Educação Jesuítica em Belém (1636 a } \\
\text { 1759) }\end{array}$ & $\begin{array}{l}\text { ANDRADE, Maria de } \mathrm{F} . \\
\text { Sarmento }\end{array}$ & $\begin{array}{l}\text { Políticas e Instituiçõ } \\
\text { Educativas }\end{array}$ \\
\hline 1985 & $\begin{array}{l}\text { Instituto Adventista Grão-Pará: uma } \\
\text { filosofia de educação. }\end{array}$ & CHENFELD, Wilson & $\begin{array}{l}\text { Políticas e Instituições } \\
\text { Educativas }\end{array}$ \\
\hline 1986 & $\begin{array}{l}\text { O Problema da Repetência na Escola } \\
\text { Estadual de } 1^{\circ} \text { Grau "Aristides Santa } \\
\text { Rosa" nos anos de } 1970 \text { e } 1985 . \\
\text { Inhangapí - Pará. }\end{array}$ & MONTEIRO, Cléia da Costa. & $\begin{array}{l}\text { Políticas e Instituições } \\
\text { Educativas }\end{array}$ \\
\hline 1993 & $\begin{array}{l}\text { O Ensino de } 2^{\circ} \text { grau no Brasil de } 1930- \\
1937 .\end{array}$ & BARBOSA, Suely Nogueira & $\begin{array}{l}\text { Políticas e Ins } \\
\text { Educativas }\end{array}$ \\
\hline 1993 & $\begin{array}{l}\text { A Organização estudantil no Curso de } \\
\text { Pedagogia da UFPA na década de } 80\end{array}$ & SOUZA, Maria Tereza Jesus & $\begin{array}{l}\text { Educação, Movimentos } \\
\text { Sociais, Etnias e Gênero }\end{array}$ \\
\hline 1994 & $\begin{array}{l}\text { Língua, Cultura e a colonização da } \\
\text { Amazônia. }\end{array}$ & $\begin{array}{l}\text { CORRÊA, Paulo S. de } \\
\text { Almeida }\end{array}$ & $\begin{array}{l}\text { Educação, Movimentos } \\
\text { Sociais, Etnias e Gênero }\end{array}$ \\
\hline 1994 & $\begin{array}{l}\text { antação do Centro de Ensino } \\
\text { CEBI) em Belém }\end{array}$ & BRAGA, Adelice Sueli & $\begin{array}{l}\text { Políticas e Instituições } \\
\text { Educativas }\end{array}$ \\
\hline 1995 & $\begin{array}{l}\text { Estrutura e funcionamento da educação } \\
\text { no município de Muaná-Pa, no período de } \\
1986 \text { a } 1994 \text {. }\end{array}$ & Clara da Silva & $\begin{array}{l}\text { Políticas e Instituições } \\
\text { Educativas }\end{array}$ \\
\hline 1995 & $\begin{array}{l}\text { Estado e Igreja no Grão-Pará: algumas } \\
\text { considerações sobre educação no } \\
\text { governo de Mendonça Furtado 1751- } \\
1759 .\end{array}$ & VASCONCELOS, Eloizo de. & $\begin{array}{l}\text { Políticas e Instituições } \\
\text { Educativas }\end{array}$ \\
\hline 1996 & $\begin{array}{l}\text { O Fracasso escolar sob a ótica de evasão } \\
\text { e nas escolas municipais de } 1^{\mathrm{a}} \text { a } 4^{\mathrm{a}} \text { séries } \\
\text { reprovação do Conj. Cidade Nova, no } \\
\text { período de } 1991 \text { a } 1995 .\end{array}$ & GURGEL, Kátia de Nazareth & $\begin{array}{l}\text { Políticas e Instituições } \\
\text { Educativas }\end{array}$ \\
\hline 1997 & 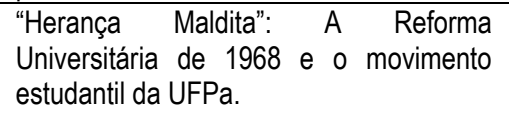 & $\begin{array}{l}\text { MIRANDA, Angelica Cristina } \\
\text { Bitar \& MELO, Shirley Borges } \\
\text { de }\end{array}$ & $\begin{array}{l}\text { Educação, Movimentos } \\
\text { Sociais, Etnias e Gênero. }\end{array}$ \\
\hline
\end{tabular}




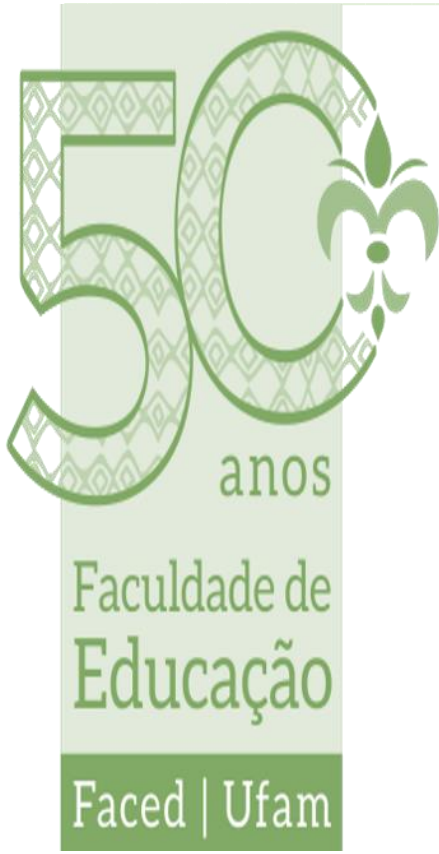

1997

O Museu Emilio Goeldi e suas contribuições para a Educação Paraense. educacional de 1942.

A reformulação do Curso de Pedagogia: a

1999 Reestruturação do Centro de Educação da UFPa Belém/PA 1994-1998: Um Olhar Sobre o Processo

O Papel Político da Educação Superior no

1999 estado do Pará: Uma análise das políticas de Extensão da UFPa no ano de 1990 a 1997. . proposta de 1997 a 2002.

História da Educação, Memória e Escolarização: Um estudo do Colégio

2003 Estadual Avertano Rocha, a partir da memória escolar de seus sujeitos

2004 Década de 90: um estudo referente ao letramento na visão das obras brasileiras. $2005 \begin{aligned} & \text { Memória educacional da Vila de } \\ & \text { Tessalônica - Irituia-PA. }\end{aligned}$

Memória e história da educação: um estudo da escolarização na localidade de
1999 O papel Social do IEP frente à reforma

\begin{tabular}{|c|c|}
\hline 1997 & $\begin{array}{l}\text { O Museu Emilio Goeldi e suas } \\
\text { contribuições para a Educação Paraense. }\end{array}$ \\
\hline 1999 & $\begin{array}{l}\text { O papel Social do IEP frente à reforma } \\
\text { educacional de } 1942 \text {. }\end{array}$ \\
\hline 1999 & $\begin{array}{l}\text { A reformulação do Curso de Pedagogia: a } \\
\text { Reestruturação do Centro de Educação } \\
\text { da UFPa Belém/PA 1994-1998: Um Olhar } \\
\text { Sobre o Processo }\end{array}$ \\
\hline 1999 & $\begin{array}{l}\text { O Papel Político da Educação Superior no } \\
\text { estado do Pará: Uma análise das políticas } \\
\text { de Extensão da UFPa no ano de } 1990 \text { a } \\
1997 .\end{array}$ \\
\hline 2000 & $\begin{array}{l}\text { A Educação de Belém no período da } \\
\text { borracha: um estudo sobre o Instituto } \\
\text { cívico-jurídico Paes de Carvalho. }\end{array}$ \\
\hline 2000 & $\begin{array}{l}\text { Piramutabas: Um estudo introdutório } \\
\text { sobre as memórias das educandas da } \\
\text { Escola Normal durante o Estado Novo. }\end{array}$ \\
\hline 2001 & $\begin{array}{l}\text { O processo de Integração das Creches no } \\
\text { sistema municipal de ensino de Belém } \\
(1998 \text { a 2001) }\end{array}$ \\
\hline 2003 & $\begin{array}{l}\text { Políticas Públicas para a Educação de } \\
\text { Jovens e Adultos: o proposto e o realizado } \\
\text { no Município de Belém de } 1997 \text { a } 2000 \text {. }\end{array}$ \\
\hline 2003 & $\begin{array}{l}\text { História, Memória e o Projeto Cabano: um } \\
\text { breve estudo em duas escolas da rede } \\
\text { municipal de Belém. }\end{array}$ \\
\hline 2003 & $\begin{array}{l}\text { O Impacto do FUNDEF na qualidade da } \\
\text { Educação Ambiental: seu reflexo nos } \\
\text { indicadores educacionais dos municípios } \\
\text { de Soure, Santarém e Altamira no período } \\
\text { de } 1996 \text { a } 2000 \text {. }\end{array}$ \\
\hline 2003 & $\begin{array}{l}\text { Políticas Públicas para a Educação Infantil } \\
\text { em Belém: proposta de } 1997 \text { a } 2002 .\end{array}$ \\
\hline 2003 & $\begin{array}{l}\text { História da Educação, Memória e } \\
\text { Escolarização: Um estudo do Colégio } \\
\text { Estadual Avertano Rocha, a partir da } \\
\text { memória escolar de seus sujeitos }\end{array}$ \\
\hline 2003 & $\begin{array}{l}\text { Ensino e Memória da escolarização da } \\
\text { llha de Cotijuba: um estudo histórico da } \\
\text { trajetória da escola XV de Agosto. }\end{array}$ \\
\hline 2004 & $\begin{array}{l}\text { Década de 90: um estudo referente ao } \\
\text { letramento na visão das obras brasileiras. }\end{array}$ \\
\hline 2004 & O FUNDEF e a imprensa escrita no Pará. \\
\hline 2005 & $\begin{array}{l}\text { A História e a memória da educação no } \\
\text { assentamento } 1^{\circ} \text { de março }\end{array}$ \\
\hline 2005 & $\begin{array}{l}\text { Resgate histórico da luta e conquista do } \\
\text { assentamento Vila Conceição. }\end{array}$ \\
\hline 2005 & $\begin{array}{l}\text { Financiamento da Educação: os impactos } \\
\text { do FUNDEF na educação do Município de } \\
\text { Irituia- PA (1997-2004) }\end{array}$ \\
\hline 2005 & $\begin{array}{l}\text { História da educação: a extraordinária } \\
\text { docência em Vila Betânia - Irituia no } \\
\text { período de } 1998 \text { a } 2001 .\end{array}$ \\
\hline 2005 & $\begin{array}{l}\text { Memória educacional da Vila de } \\
\text { Tessalônica - Irituia - PA. }\end{array}$ \\
\hline 200 & $\begin{array}{l}\text { Memória e história da educação: um } \\
\text { estudo da escolarização na localidade de } \\
\text { Galileia (Irituia - Pará) na perspectiva de } \\
\text { seus sujeitos. }\end{array}$ \\
\hline
\end{tabular}

\begin{tabular}{|c|c|}
\hline 1997 & $\begin{array}{l}\text { O Museu Emilio Goeldi e suas } \\
\text { contribuições para a Educação Paraense. }\end{array}$ \\
\hline 1999 & $\begin{array}{l}\text { O papel Social do IEP frente à reforma } \\
\text { educacional de } 1942 \text {. }\end{array}$ \\
\hline 1999 & $\begin{array}{l}\text { A reformulação do Curso de Pedagogia: a } \\
\text { Reestruturação do Centro de Educação } \\
\text { da UFPa Belém/PA 1994-1998: Um Olhar } \\
\text { Sobre o Processo }\end{array}$ \\
\hline 1999 & $\begin{array}{l}\text { O Papel Político da Educação Superior no } \\
\text { estado do Pará: Uma análise das políticas } \\
\text { de Extensão da UFPa no ano de } 1990 \text { a } \\
1997 .\end{array}$ \\
\hline 2000 & $\begin{array}{l}\text { A Educação de Belém no período da } \\
\text { borracha: um estudo sobre o Instituto } \\
\text { cívico-jurídico Paes de Carvalho. }\end{array}$ \\
\hline 2000 & $\begin{array}{l}\text { Piramutabas: Um estudo introdutório } \\
\text { sobre as memórias das educandas da } \\
\text { Escola Normal durante o Estado Novo. }\end{array}$ \\
\hline 2001 & $\begin{array}{l}\text { O processo de Integração das Creches no } \\
\text { sistema municipal de ensino de Belém } \\
(1998 \text { a 2001) }\end{array}$ \\
\hline 2003 & $\begin{array}{l}\text { Políticas Públicas para a Educação de } \\
\text { Jovens e Adultos: o proposto e o realizado } \\
\text { no Município de Belém de } 1997 \text { a } 2000 \text {. }\end{array}$ \\
\hline 2003 & $\begin{array}{l}\text { História, Memória e o Projeto Cabano: um } \\
\text { breve estudo em duas escolas da rede } \\
\text { municipal de Belém. }\end{array}$ \\
\hline 2003 & $\begin{array}{l}\text { O Impacto do FUNDEF na qualidade da } \\
\text { Educação Ambiental: seu reflexo nos } \\
\text { indicadores educacionais dos municípios } \\
\text { de Soure, Santarém e Altamira no período } \\
\text { de } 1996 \text { a } 2000 \text {. }\end{array}$ \\
\hline 2003 & $\begin{array}{l}\text { Políticas Públicas para a Educação Infantil } \\
\text { em Belém: proposta de } 1997 \text { a } 2002 .\end{array}$ \\
\hline 2003 & $\begin{array}{l}\text { História da Educação, Memória e } \\
\text { Escolarização: Um estudo do Colégio } \\
\text { Estadual Avertano Rocha, a partir da } \\
\text { memória escolar de seus sujeitos }\end{array}$ \\
\hline 2003 & $\begin{array}{l}\text { Ensino e Memória da escolarização da } \\
\text { llha de Cotijuba: um estudo histórico da } \\
\text { trajetória da escola XV de Agosto. }\end{array}$ \\
\hline 2004 & $\begin{array}{l}\text { Década de 90: um estudo referente ao } \\
\text { letramento na visão das obras brasileiras. }\end{array}$ \\
\hline 2004 & O FUNDEF e a imprensa escrita no Pará. \\
\hline 2005 & $\begin{array}{l}\text { A História e a memória da educação no } \\
\text { assentamento } 1^{\circ} \text { de março }\end{array}$ \\
\hline 2005 & $\begin{array}{l}\text { Resgate histórico da luta e conquista do } \\
\text { assentamento Vila Conceição. }\end{array}$ \\
\hline 2005 & $\begin{array}{l}\text { Financiamento da Educação: os impactos } \\
\text { do FUNDEF na educação do Município de } \\
\text { Irituia- PA (1997-2004) }\end{array}$ \\
\hline 2005 & $\begin{array}{l}\text { História da educação: a extraordinária } \\
\text { docência em Vila Betânia - Irituia no } \\
\text { período de } 1998 \text { a } 2001 .\end{array}$ \\
\hline 2005 & $\begin{array}{l}\text { Memória educacional da Vila de } \\
\text { Tessalônica - Irituia - PA. }\end{array}$ \\
\hline 200 & $\begin{array}{l}\text { Memória e história da educação: um } \\
\text { estudo da escolarização na localidade de } \\
\text { Galileia (Irituia - Pará) na perspectiva de } \\
\text { seus sujeitos. }\end{array}$ \\
\hline
\end{tabular}

\begin{tabular}{|c|c|}
\hline 1997 & $\begin{array}{l}\text { O Museu Emilio Goeldi e suas } \\
\text { contribuições para a Educação Paraense. }\end{array}$ \\
\hline 1999 & $\begin{array}{l}\text { O papel Social do IEP frente à reforma } \\
\text { educacional de } 1942 \text {. }\end{array}$ \\
\hline 1999 & $\begin{array}{l}\text { A reformulação do Curso de Pedagogia: a } \\
\text { Reestruturação do Centro de Educação } \\
\text { da UFPa Belém/PA 1994-1998: Um Olhar } \\
\text { Sobre o Processo }\end{array}$ \\
\hline 1999 & $\begin{array}{l}\text { O Papel Político da Educação Superior no } \\
\text { estado do Pará: Uma análise das políticas } \\
\text { de Extensão da UFPa no ano de } 1990 \text { a } \\
1997 .\end{array}$ \\
\hline 2000 & $\begin{array}{l}\text { A Educação de Belém no período da } \\
\text { borracha: um estudo sobre o Instituto } \\
\text { cívico-jurídico Paes de Carvalho. }\end{array}$ \\
\hline 2000 & $\begin{array}{l}\text { Piramutabas: Um estudo introdutório } \\
\text { sobre as memórias das educandas da } \\
\text { Escola Normal durante o Estado Novo. }\end{array}$ \\
\hline 2001 & $\begin{array}{l}\text { O processo de Integração das Creches no } \\
\text { sistema municipal de ensino de Belém } \\
(1998 \text { a 2001) }\end{array}$ \\
\hline 2003 & $\begin{array}{l}\text { Políticas Públicas para a Educação de } \\
\text { Jovens e Adultos: o proposto e o realizado } \\
\text { no Município de Belém de } 1997 \text { a } 2000 \text {. }\end{array}$ \\
\hline 2003 & $\begin{array}{l}\text { História, Memória e o Projeto Cabano: um } \\
\text { breve estudo em duas escolas da rede } \\
\text { municipal de Belém. }\end{array}$ \\
\hline 2003 & $\begin{array}{l}\text { O Impacto do FUNDEF na qualidade da } \\
\text { Educação Ambiental: seu reflexo nos } \\
\text { indicadores educacionais dos municípios } \\
\text { de Soure, Santarém e Altamira no período } \\
\text { de } 1996 \text { a } 2000 \text {. }\end{array}$ \\
\hline 2003 & $\begin{array}{l}\text { Políticas Públicas para a Educação Infantil } \\
\text { em Belém: proposta de } 1997 \text { a } 2002 .\end{array}$ \\
\hline 2003 & $\begin{array}{l}\text { História da Educação, Memória e } \\
\text { Escolarização: Um estudo do Colégio } \\
\text { Estadual Avertano Rocha, a partir da } \\
\text { memória escolar de seus sujeitos }\end{array}$ \\
\hline 2003 & $\begin{array}{l}\text { Ensino e Memória da escolarização da } \\
\text { llha de Cotijuba: um estudo histórico da } \\
\text { trajetória da escola XV de Agosto. }\end{array}$ \\
\hline 2004 & $\begin{array}{l}\text { Década de 90: um estudo referente ao } \\
\text { letramento na visão das obras brasileiras. }\end{array}$ \\
\hline 2004 & O FUNDEF e a imprensa escrita no Pará. \\
\hline 2005 & $\begin{array}{l}\text { A História e a memória da educação no } \\
\text { assentamento } 1^{\circ} \text { de março }\end{array}$ \\
\hline 2005 & $\begin{array}{l}\text { Resgate histórico da luta e conquista do } \\
\text { assentamento Vila Conceição. }\end{array}$ \\
\hline 2005 & $\begin{array}{l}\text { Financiamento da Educação: os impactos } \\
\text { do FUNDEF na educação do Município de } \\
\text { Irituia- PA (1997-2004) }\end{array}$ \\
\hline 2005 & $\begin{array}{l}\text { História da educação: a extraordinária } \\
\text { docência em Vila Betânia - Irituia no } \\
\text { período de } 1998 \text { a } 2001 .\end{array}$ \\
\hline 2005 & $\begin{array}{l}\text { Memória educacional da Vila de } \\
\text { Tessalônica - Irituia - PA. }\end{array}$ \\
\hline 2005 & $\begin{array}{l}\text { Memória e história da educação: um } \\
\text { estudo da escolarização na localidade de } \\
\text { Galileia (Irituia - Pará) na perspectiva de } \\
\text { seus sujeitos. }\end{array}$ \\
\hline
\end{tabular}
seus sujeitos.

CASTILHO, Ana C. M. da

Motta

GOMES, Erick do Socorro

Moraes

PONTES, Alda Renata

Sarges \& SCALABRIN,

Rosemeri

FLORES SOBRINHO,

Cláudia Mônica ; BEZERRA, Políticas e Instituições

Ilton Campos \& DA SILVA, Educativas

Maria Regina Ferreira.

RAMOS, Carlos Alberto dos S Educação Profissional

LOBATO, Hilda Karina

Memória e Patrimônio

Educativo.

SOUZA, Doracy Moares

Políticas e Instituições

Educativas

FERREIRA, Dilmara Teixeira

\& SILVA, Teodora C. da Silva da.

Políticas e Instituições

Educativas

VANZELER, Gilmara M. Políticas e Instituições

Magalhães \& ESPINDOLA, $\quad$ Educativas

Lilian C. Machado.

CARVALHO, Fabricio Aarão

Políticas e Instituições Educativas

CARDOSO, Glauciane foro \& SANTA ROSA, Michelle de Souza

Políticas e Instituições Educativas

SILVA, Telma Jarina Galvão da \& SILVA, Valéria Foro da

Memória e Patrimônio Educativo.

COSTA, Nelson Tavares da; Políticas e Instituições \& SOUZA, Maria Leite de. Educativas

NASCIMENTO, Damásia Disciplinas Escolares e Sulina do \& RIBEIRO, Hudson Ensino de História da Uillan Amazonas Educação.

ALVES, Luana $C$ dos Passos Imprensa e Projetos Educacionais

ALMEIDA, Angelita Educação, Movimentos Magalhães de Sociais, Etnias e Gênero

SILVA, Maria da Penha Educação, Movimentos Viana. Sociais, Etnias e Gênero

SANTOS, Maria Auxiliadora

Cirino dos \& MAIA, Rozinéia Vitório de.

Políticas e Instituições Educativas

ARAÚJO, Antoniel Lima \& Formação e Profissão SOUZA, Jonivaldo Castro de. Docente

VERA CRUZ, Cirlete de Oliveira da \& SILVA, Luzenita Moreira da.

Memória e Patrimônio Educativo

VERA CRUZ, Denise Soares da \& GONZAGA, Laudeci Batista.
Memória e Patrimônio Educativo 


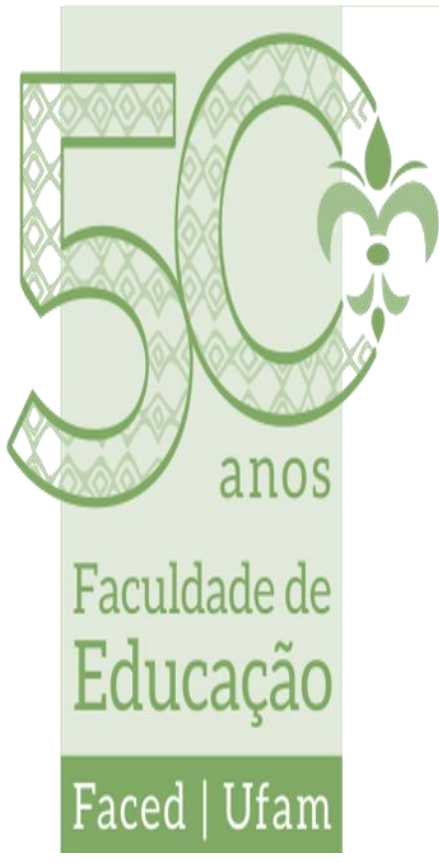

2005

Sa escola na comunidade São

Jose, município de Novo Progresso Estado do Pará.

0 Atual modelo de expansão da

2006 Universidade Federal do Pará (20012004)

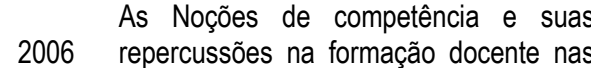
décadas de 1980 a 1990.

2006 A Concepção de Educação de José Veríssimo na obra A Educação Nacional

0 perfil técnico-teórico dos TCCs em educação de jovens e adultos elaborados

2007 pelos graduandos do curso de pedagogia do Centro de Educação da UFPA no período de 2001 a 2006

\begin{tabular}{|c|c|c|c|}
\hline 2008 & $\begin{array}{l}\text { A repetência e a desistência nas } 5^{\text {as }} \text { séries } \\
\text { da Escola Getúlio Vargas, na disciplina } \\
\text { matemática, no período } 2004 \text { a } 2007\end{array}$ & $\begin{array}{l}\text { ALMEIDA, Laurenita Pereira } \\
\text { \& DIAS, Maria Rosa Araújo. }\end{array}$ & $\begin{array}{l}\text { Disciplinas Escolares e } \\
\text { Ensino de História da } \\
\text { Educação }\end{array}$ \\
\hline 2008 & $\begin{array}{l}\text { A Política de Gestão Educacional no } \\
\text { Município de Muaná de } 1990 \text { a 2007: um } \\
\text { enfoque sobre a política de Conselhos } \\
\text { Escolares e sua materialização na Escola } \\
\text { Municipal Caminho do Saber. }\end{array}$ & $\begin{array}{l}\text { COELHO, Josenilda de Jesus } \\
\text { da Silva \& CORRÊA, João do } \\
\text { Vale. }\end{array}$ & $\begin{array}{l}\text { Políticas e Instituições } \\
\text { Educativas }\end{array}$ \\
\hline 2013 & $\begin{array}{l}\text { As políticas públicas em EJA no governo } \\
\text { do presidente Luiz Inácio Lula da Silva: } \\
\text { período } 2003 \text { a } 2007 \text {. }\end{array}$ & PESSOA, Karla M. S. & $\begin{array}{l}\text { Políticas e Instituições } \\
\text { Educativas }\end{array}$ \\
\hline 2013 & $\begin{array}{l}\text { As contribuições de Manuel Ancízar para } \\
\text { a formação do pensamento político- } \\
\text { educacional da Colômbia (1812 - 1882). }\end{array}$ & FERNANDES, Aline S. & $\begin{array}{l}\text { Intelectuais e Projetos } \\
\text { Educacionais }\end{array}$ \\
\hline 2014 & $\begin{array}{l}\text { Escola Cidade de Emaús na memória de } \\
\text { egressos. }\end{array}$ & SILVA, Cleonice A. P. & $\begin{array}{l}\text { Memória e Patrimônio } \\
\text { Educativo }\end{array}$ \\
\hline 2014 & $\begin{array}{l}\text { Política de valorização docente no } \\
\text { contexto do FUNDEF: breve análise da } \\
\text { remuneração docente a partir dos dados } \\
\text { do Censo do Professor } 1997 \text { e } 2003 \text {. }\end{array}$ & PIMENTEL, Bárbara S. & $\begin{array}{l}\text { Políticas e Instituições } \\
\text { Educativas }\end{array}$ \\
\hline 2014 & $\begin{array}{l}\text { Educação religiosa no Brasil e na } \\
\text { Amazônia. }\end{array}$ & TAVARES, Ana L. L. & $\begin{array}{l}\text { Políticas e Instituições } \\
\text { Educativas }\end{array}$ \\
\hline 2015 & $\begin{array}{l}\text { Apontamentos para a história e memória } \\
\text { da educação na Amazônia: a Escola } \\
\text { Fernando Ferrari (1962-1985). }\end{array}$ & REIS, Vera L. Q. & $\begin{array}{l}\text { Memória e Patrimônio } \\
\text { Educativo }\end{array}$ \\
\hline 2015 & $\begin{array}{l}\text { Educação feminina na Belém da Belle } \\
\text { Époque (1890-1902). }\end{array}$ & SOUSA, Brígida R. V. & $\begin{array}{l}\text { Educação, Movimentos } \\
\text { Sociais, Etnias e Gênero }\end{array}$ \\
\hline 2015 & $\begin{array}{l}\text { Orientações curriculares para o ensino de } \\
\text { história nos anos iniciais do ensino } \\
\text { fundamental: entre o local e o nacional } \\
(1980-2012) \text {. }\end{array}$ & CARMO, Adele S. F. & $\begin{array}{l}\text { Disciplinas Escolares e } \\
\text { Ensino de História da } \\
\text { Educação }\end{array}$ \\
\hline
\end{tabular}

A violência sexual contra crianças $e$ adolescentes no estado do Pará nos anos

2015 de 2010 a 2014: uma análise a partir das notícias divulgadas pelo jornal Diário do Pará.

\begin{tabular}{cl}
\hline 2015 & $\begin{array}{l}\text { A educação na Ditadura Militar: um olhar } \\
\text { sobre a disciplina Estudos Sociais. }\end{array}$ \\
\hline 2015 & $\begin{array}{l}\text { As ações desenvolvidas pelo Programa } \\
\text { Jepiara para o enfrentamento da violência } \\
\text { sexual contra crianças e adolescentes nos } \\
\text { anos de } 2004 \text { a } 2013 .\end{array}$ \\
\hline 2016 & $\begin{array}{l}\text { História da infância no Brasil: uma breve } \\
\text { retrospectiva da caridade à filantropia, no } \\
\text { período da colônia ao início da República. }\end{array}$ \\
\hline $2016 \quad \begin{array}{l}\text { O ensino médio no estado do Pará e os } \\
\text { indicadores de oferta nas regiões de } \\
\text { integração do Marajó e metropolitana de } \\
\text { Belém no período de 2010 a 2014. }\end{array}$
\end{tabular}

FALEIRO, Cláudio Antonio \& Memória e Patrimônio ALMEIDA, Joarez Araújo de. Educativo.

AZEVEDO, Silvia Monteiro de Políticas e Instituições Educativas

PANTOJA JUNIOR, Paulo

Rodrigues \& ROCHA, Sidcley Cesar Costa.

PRESTES, Carlos Alberto

Formação e Profissão

Docente

Intelectuais e Projetos Educacionais

SANTOS, Marluce França Teoria da História e Santana dos. Historiografia

COELHO, Josenilda de Jesus da Silva \& CORRÊA, João do

Políticas e Instituições Educativas

Políticas e Instituições Intelectuais e Projetos ducacionais

$\begin{array}{ll}\text { SOUZA, Jessica G. F. } & \begin{array}{l}\text { Imprensa e Impressos } \\ \text { Educacionais }\end{array} \\ \text { COSTA, Aline F. } & \begin{array}{l}\text { Disciplinas Escolares e } \\ \text { Ensino de História da } \\ \text { Educação }\end{array} \\ \text { MERCÊS, Thais S. T. } & \begin{array}{l}\text { Processos Educativos e } \\ \text { Práticas de Sociabilidade } \\ \text { Não-Escolares }\end{array} \\ \text { CHAGAS, Ainêe C.P. } & \text { Educação e Gerações } \\ \text { NORONHA, Gean F. } & \begin{array}{l}\text { Políticas e Instituições } \\ \text { Educativas }\end{array}\end{array}$




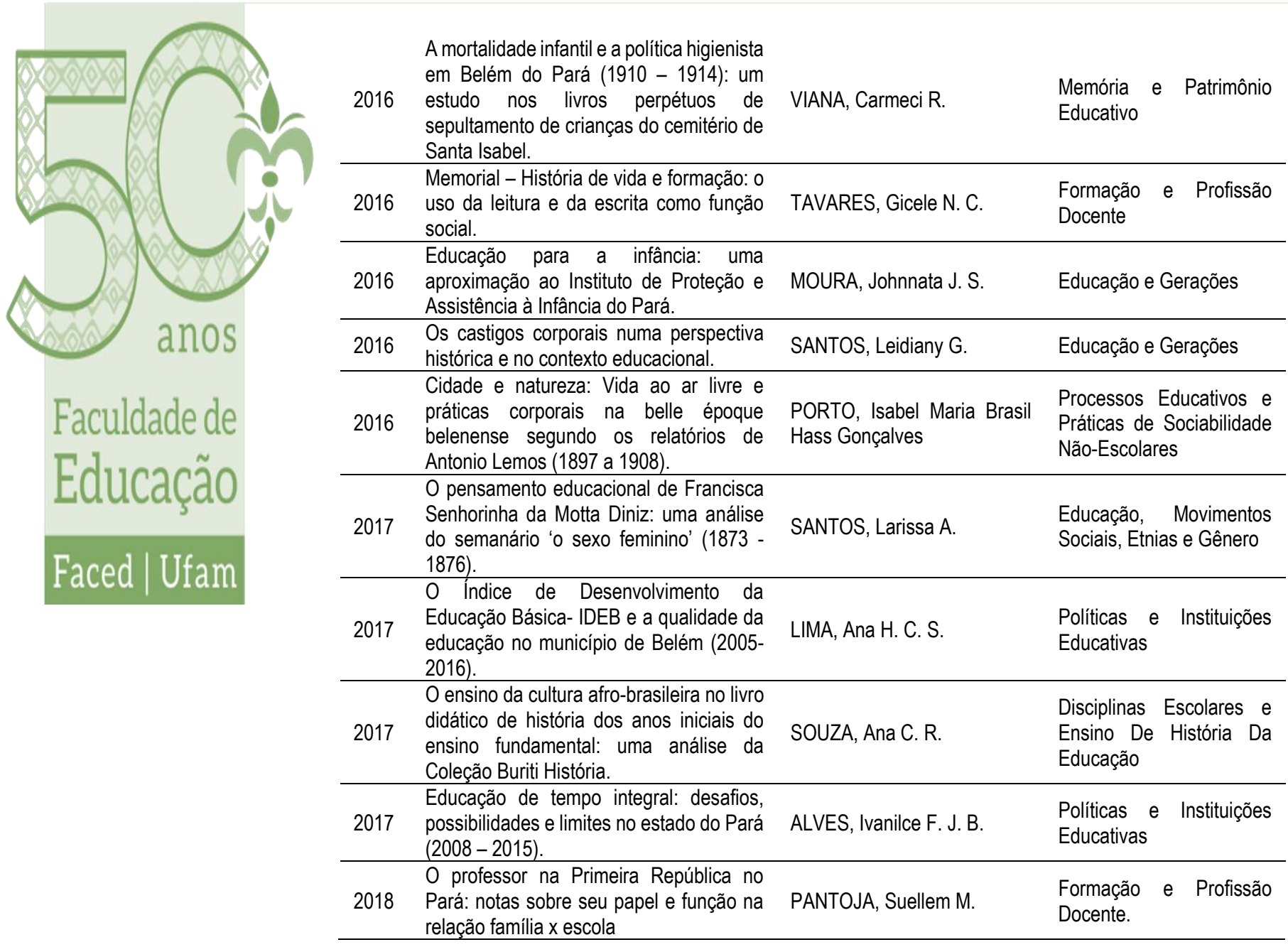

Fonte: Elaborada pelos autores, com base em dados da Biblioteca Setorial do ICED/UFPA.

\section{OS EIXOS TEMÁTICOS ADOTADOS NOS TRABALHOS}

Chamamos a atenção para o fato de que nessa etapa do estudo fizemos um exercício preliminar de identificação e classificação dos trabalhos conforme um padrão já consolidado, qual seja, o da SBHE. Havia muitos trabalhos cujos títulos não explicitavam o que investigaram e seu resumo não foi suficientemente claro para definir um eixo; além disso, encontramos trabalhos que poderiam ser inseridos em mais de um eixo.

Dentre os 61 trabalhos levantados, 25 pertencem ao eixo temático "Políticas e Instituições Educativas", ou seja, seus autores pesquisaram a história e memória das instituições educativas, analisando seu processo de criação, institucionalização e expansão. 


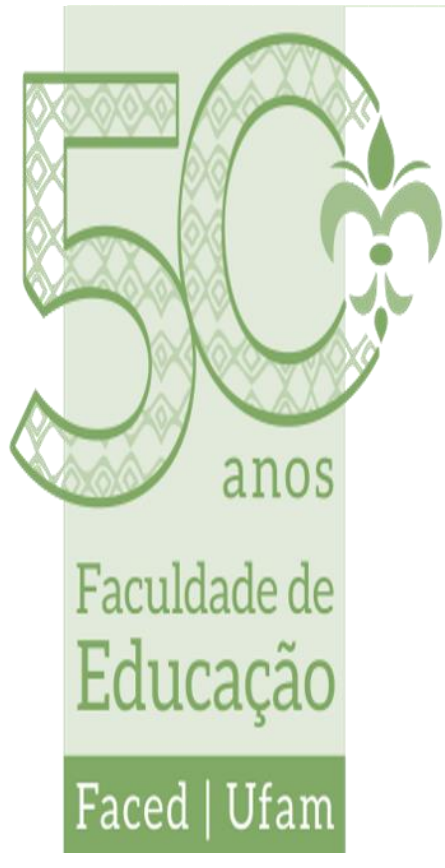

Dentre os trabalhos classificados no eixo citado, alguns tiveram como foco principal as Instituições Escolares. O primeiro é o de Maria Andrade (1983), que aborda a Educação Jesuítica. Ainda no mesmo eixo, há constância de trabalhos relacionados ao Fundo de Manutenção e Desenvolvimento do Ensino Fundamental e de Valorização do Magistério (FUNDEF) como, por exemplo, nos TCCs de Fabricio Carvalho (2003), Rosinéia Maia (2005) e Bárbara Pimentel (2014), destacando a valorização da remuneração dos professores da educação básica no âmbito do FUNDEF. O Ensino rural foi abordado nos trabalhos de Cléia Monteiro (1986) e Clara Ferrão (1995), que buscaram compreender a problemática que circunda o cenário educacional na zona rural. Dilmara Ferreira e Teodora Silva (2003) e Karla Pessoa (2013) discutiram a Educação de Jovens e Adultos (EJA) como ação de inclusão social e as políticas públicas relacionadas a ela. As políticas no âmbito da UFPA suscitaram interesse nos alunos, como vimos nos trabalhos de Silvia Azevedo (2006) e Cláudia Mônica Flores, Ilton Bezerra e Maria da Silva (1999). Por fim, o TCC de Suely Barbosa (1993) e Kátia Gurgel (1996) discutiram as Reformas Educacionais da Educação em cenário nacional e a dificuldade de aprendizado.

O eixo da "Formação e Profissão Docente" foi abordado em cinco trabalhos, que analisaram a memória da formação dos próprios autores, assim como da instituição em que foram formados. Alda Pontes e Rosemeri Scalabrin (1999), Paulo Pantoja e Sidcley Rocha (2006) e Gicele Tavares (2016) trazem uma investigação sobre o processo de reformulação do Curso de Pedagogia. Antoniel Araújo e Jonivaldo Souza (2005) e Suellem Pantoja (2018) abordaram o papel do professor em diferentes contextos e épocas.

O eixo "Disciplinas Escolares e Ensino da História da Educação" foi abordado cinco vezes, quando os autores trataram acerca da história do ensino e das disciplinas escolares. Damásia Nascimento e Hudson Ribeiro (2004), Laurenita Almeida (2008), Adele Carmo (2015), investigaram estudos produzidos na década de 90, o papel fundamental do professor na formação dos alunos e a 
análise de orientações curriculares para o ensino de história. Aline Costa (2015) e Ana Souza (2017) abordaram os conteúdos e métodos nas disciplinas Estudos Sociais e História em diferentes cenários.

O eixo "Educação e Gerações" que trata das relações geracionais em diversos contextos foi a tônica em três trabalhos. Ainêe Chagas (2016), Johnnata Moura (2016) e Leidiany Santos (2016), pesquisaram a respeito da história da infância no Brasil, o cenário educacional atual relacionado com as ideias higienistas e os castigos corporais na escola.

O eixo "Educação, Movimentos Sociais, Etnias e Gêneros", que Faced | Ufam pesquisa os processos educativos abrangendo movimentos sociais, grupos étnicos/raciais e de gênero foi abordado em sete trabalhos: Maria Tereza Souza (1993), resgatou a história da Organização Estudantil no Curso de Pedagogia da década de 80. Paulo Sérgio Corrêa (1994), Angélica Miranda e Shirley Melo (1997), Angelita Almeida (2005), Maria da Penha (2005), trataram do estudo da História da colonização da Amazônia, processos da Reforma Universitária implementada no regime militar e a história do Assentamento $1^{\circ}$ de Março. Brígida Sousa (2015) e Larissa Santos (2017) pesquisaram sobre a consolidação da escola na formação de docentes do sexo feminino em contextos variados. No eixo "Intelectuais e Projetos Educacionais", que aborda a história e a produção de intelectuais do campo da Educação, temos o trabalho de Carlos Alberto Prestes (2006) e Aline Fernandes (2013) que estudaram José Veríssimo e Manuel Ancízar, respectivamente.

"Imprensa e Impresso Escritos", eixo que pesquisa a imprensa como meio para a reflexão crítica sobre a sociedade, foi adotado em dois trabalhos: Luana Alves (2004) e Jéssica Souza (2015) investigaram notícias em jornais do Estado referentes ao FUNDEF e a violência sexual no Pará, respectivamente

Processos e práticas de guarda, seleção, catalogação e preservação de acervos escolares são características do eixo "Memória e Patrimônio Educativo", abordado nos TCCs de Hilda Lobato (2000), Telma Silva e Valéria Silva (2003), Cirlete Vera Cruz e 


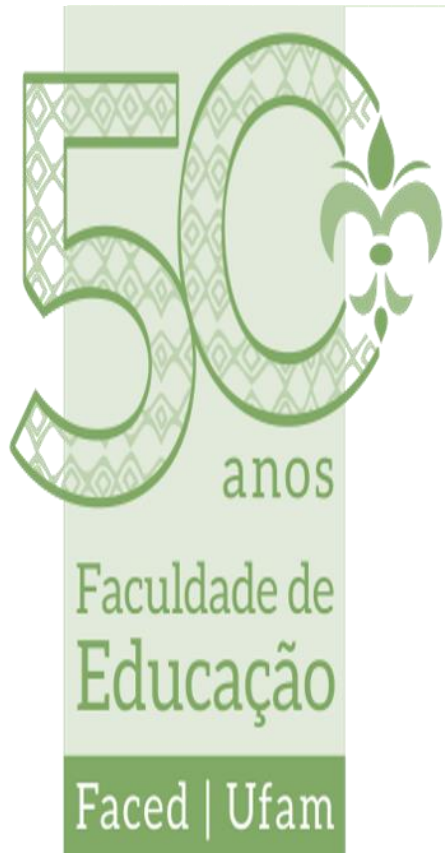

Luzenita Silva (2005), Denise Vera Cruz e Laudeci Gonzaga (2005), Cláudio Faleiro e Joarez Almeida (2005), Cleonice Silva (2014), Vera Reis (2015) e Carmeci Viana (2016). Os trabalhos tiveram temas relacionados desde a história de Colégios paraenses, o resgate histórico da Vila de Tessalônica em Irituia - PA, até temas referentes à mortalidade infantil em Belém tendo como fonte os Livros Perpétuos de Sepultamento de Crianças no Cemitério de Santa Izabel do Pará. O eixo "Educação Profissional", pesquisa sobre origens históricas de educação profissional. Carlos Ramos (2000) discutiu a sistemática do Instituto Cívico-Jurídico Paes de Carvalho.

O eixo "Processos Educativos e Práticas de Sociabilidade NãoEscolares", referente aos estudos da história dos processos educativos não escolares, foi o adotado por três trabalhos: Ana Castilho (1997), Thais Mercês (2015) e Isabel Maria Porto (2016). O eixo "Teoria da História e Historiografia", definido pelas relações entre História, Historiografia e Educação, foi desenvolvido uma única vez, por Marluce Santos (2007).

\section{CONSIDERAÇÕES FINAIS}

O estudo sobre os Trabalhos de Conclusão no Curso de Pedagogia da UFPA entre 1983 e 2018 nos possibilitou compreender melhor o cenário da produção dos acadêmicos do referido Curso, assim como suas preferências temáticas. A respeito do conjunto dos TCCs, vimos que alguns dos principais focos dos autores foram a Educação Infantil, a Política Educacional e a Educação Especial na formação do professor.

Levando-se em consideração os estudos no campo da História da Educação, identificamos que, entre os trabalhos, certas temáticas aparecem em quantidade muito mais expressiva em detrimento de outras e que, de forma geral, a História da Educação pode ser considerada como de média produção, sobretudo se considerarmos outros temas que aparecem com baixíssima frequência. 
Percebemos com nossa investigação que a maior parte dos TCCs de História da Educação abordou, principalmente, o processo de implantação, o papel social, as influências, a trajetória e os desdobramentos históricos das Instituições Escolares. As políticas na Educação Superior, na Educação de Jovens e Adultos, no Ensino Rural e na Formação de Professores, também foram bastante exploradas. Também constatamos um interesse significativo em relação às políticas associadas às instituições educativas, afinal, mais da metade dos autores desenvolveu sua pesquisa neste assunto; enquanto os trabalhos referentes ao eixo "Formação e Profissão docente" não teve o mesmo alcance, apesar do Curso de Pedagogia ter como objetivo a formação destes profissionais. Outros eixos também foram abordados nos TCCs, porém não de forma expressiva, como o eixo "Políticas e Instituições Educativas".

Em síntese, no que tange ao conteúdo dos TCCs do Curso de Pedagogia da UFPA, percebemos uma grande variedade de temas ao longo de sua história; inclusive em se tratando da História da Educação, pois foi possível observar que, neste campo, os temas tratados também foram variados e apresentaram abordagens muito pertinentes e, obviamente, contribuíram para o debate no âmbito desta disciplina. Finalmente, destacamos que, mesmo com uma produção de média intensidade, a História da Educação ainda necessita de maior estímulo no seio do corpo discente, de forma a ampliar o interesse no meio discente, dada sua grande relevância para a formação do pedagogo e de outros educadores.

\section{REFERÊNCIAS}

ALVES, Laura. M. S. A.; NERY, Vitor S. C.; SILVA, Livia S.da. Cartografia das produções em história da educação nos Programas de Pós graduação em Educação no Pará (2005-2018). V,19. In: Revista Brasileira de História da Educação, abril/ 2019.

BENCOSTTA, Marcus. L. A escrita da arquitetura escolar na historiografia da educação brasileira (1999-2018). In: Revista Brasileira de História da Educação, abril/2019.

BRANDÃO, Carlos R.. Identidade e Etnia. Editora Brasiliense, 1986. 


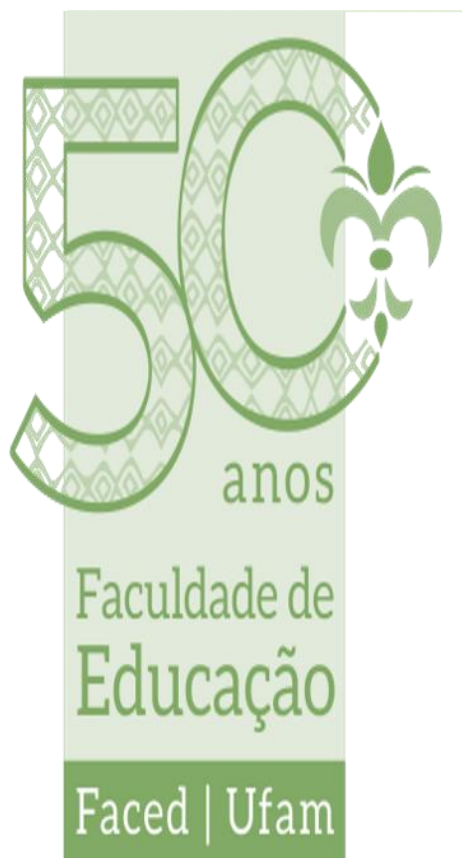

BRASIL. NBR 14724: informação e documentação: trabalhos acadêmicos: apresentação. 3. ed. Rio de Janeiro, 2011.

CORDEIRO, Cecília S. História e história da historiografia: alguns apontamentos. In: XXVIII Simpósio Nacional de História - Anpuh, 2015, Florianópolis - SC. XXIII Simpósio Nacional de História. Lugares dos historiadores: velhos e novos desafios, 2015.

FERREIRA, Norma S. de A. As pesquisas denominadas "Estado da arte". In: Educação \& sociedade, v. 23, p. 257, 2002.

ICED. Catálogo de Trabalhos de Conclusão de Curso. Faculdade de Educação, Biblioteca Setorial do ICED, 2018.

RIBEIRO, Drielle L. G. S. ; CASTRO, Regina C. A. de M.. ESTADO DA ARTE, O QUE É ISSO AFINAL? In: III Congresso Nacional de Educação CONEDU, 2016, João Pessoa. CONEDU Congresso Nacional de Educação. Campina Grande: Realize, 2016. v. 1. p. 16591669.

ROMANOWSKI, J. Paulin; ENS, Romilda T. As pesquisas denominadas do tipo "Estado da Arte". In: Diálogos Educacionais, v. 6, n. 6, p. 37-50, 2006.

SAVIANI, Dermeval. História da história da educação no Brasil: um balanço prévio e necessário. Eccos Revista Científica, v. 10, n. Esp, p. 147-167, 2008.

SILVA, Kalina. V.; SILVA, Maciel H.. Dicionário de conceitos históricos. São Paulo: Contexto, 2005. 